\title{
Factors associated with low level of health information utilization in resources limited setting, Eastern Ethiopia
}

\author{
Kidist Teklegiorgis, Kidane Tadesse, Gebremeskel Mirutse, Wondwossen Terefe \\ Department of Public Health, College of Health Sciences, Mekelle University, Mekelle, Ethiopia \\ Email address: \\ kidtek6@gmail.com (Teklegiorgis K.), Kiducs98@yahoo.com (K. Tadesse), gebramskelmirutse@ yahoo.com (G. Mirutse), \\ kidwonyt4@gmail.com (W. Terefe)
}

\section{To cite this article:}

Kidist Teklegiorgis, Kidane Tadesse, Gebremeskel Mirutse, Wondwossen Terefe. Factors Associated with Low Level of Health Information Utilization in Resources Limited Setting, Eastern Ethiopia. International Journal of Intelligent Information Systems.

Vol. 3, No. 6, 2014, pp. 69-75. doi: 10.11648/j.ijiis.20140306.13

\begin{abstract}
Health information system (HIS) is a system that integrates data collection, processing, reporting and use of the information necessary for improving health service effectiveness and efficiency through better management at all levels of health services. Despite the credible use of HIS for evidence based decision making, countries with the highest burden of ill health and the most in-needs for accurate and timely data have the weakest HIS in the vast majority of world's poorest countries. The main of this study was to assess the level of information utilization and identify factors affecting information use in, Ethiopian, health facilities. A cross sectional study was conducted by using structured questioners in Dire Dawa administration health facilities. All unit/department heads from all government health facilities were selected. The data was analyzed using STATA version 11. Frequency and percentages was computed to present the descriptive findings. Association between variables was computed using binary logistic regression. Over all utilization of health information was found to be $53.1 \%$. Friendly format for reporting and managers provide regular feed back to their staff were found to be significantly associated with health information utilization, and their strength were (AOR=2.796,95\% CI[1.478,5.288]) and $(\mathrm{AOR}=2.195,95 \% \mathrm{CI}[1.213,3.974])$ respectively. Overall HIS utilization was found to be below the national expectation level. Low utilization of HIS was found in health posts than health centers and hospitals. There was also shortage of assigned HIS personnel, separate HIS office and assigned budget for HIS in majority of units/departments.
\end{abstract}

Keywords: HMIS, HIS, Ethiopia, Information Utilization

\section{Introduction}

A health information system (HIS) is a system that integrates data collection, processing, reporting and use of the information necessary for improving health service effectiveness and efficiency through better management at all levels of health services. Maintaining a good HMIS is an essential part in strengthening the health system $(1,2)$. In 2007, the World Health Assembly (WHA) passed a resolution on strengthening of HIS. The resolution acknowledges that sound information is critical in framing evidence based health policy and making decision and it is fundamental for monitoring program towards internationally agreed health related development goals. Although HMIS forms a backbone for strong health systems, most developing countries still face a challenge in strengthening routine health information systems $(3,4)$.
In a good HMIS, data collection should be similar with the data requirements of users (only relevant data) and to the available processing capabilities, also the information generated should be simple to obtain and only the minimum required information must be collected, so that analysis can be done quickly. Feedback to the providers of the health data is an essential component of any reporting system $(5,6)$. The Ethiopian Federal Ministry of Health (FMOH) has emphasized the HMIS as a key component for successful implementation of Health Sector Development Program (HSDP) strategic plan. The core health indicators come from routine health service and administrative records through HMIS and M\&E and are complementary processes standardizing of indicator definitions and data recording and reporting forms; integration of data from different programs 
into a shared channels improves health system efficiency and effectiveness (7-9).

The value of health information is determined by its utilization in decision-making. Public health decision-making is critically dependent on the timely availability of sound data. Developing countries are reported to have a large amount of unreliable health data, poor human resources and poor information technology infrastructure, hence effective HIS are needed to improve these problems. In Ethiopia data quality and utilization of health information remains weak, particularly at primary health care facilities and district levels and the major associated factors includes (10-15).

\section{Methods and Materials}

\subsection{Study Setting}

This study was conducted in Dire Dawa administration, Ethiopia, health facilities from March 01-31/2013. Dire Dawa is one of the two chartered cities in Ethiopia (the other being the capital, Addis Ababa). Dire Dawa lies in the eastern part of Ethiopia which is $501 \mathrm{~km}$ away from Addis Ababa. The administration has one governmental hospital, 16 health centers and 34 health posts. Except the regional health bureau, it has no zonal or district health bureau.

Based on the 2007 Census conducted by the Central Statistical Agency of Ethiopia (CSA), Dire Dawa has a total population of 342,827 , of whom 171,930 were men and 170,897 women; 232,854 or $69.92 \%$ of the population are considered urban inhabitants, with an estimated area of 1,231.20 square kilometers [32].

\subsection{Study Design}

We used a facility based cross sectional study design; all department heads of health facilities have been interviewed at point in time, to assess the level of information utilization and associated factors.

\subsection{Study Participants and Sampling}

The source population was all governmental health facilities found in Dire Dawa administration. The study population was all unit/department head of hospital, health centers and health posts. Since all health facilities in the administration currently implement HMIS, all unit/department heads from all health facilities were included in the study. In Dire Dawa Administration, there are a total of 267 unit/department heads from all health facilities including health posts. We conduct a census of unit/department heads i.e. all department heads have been included in this study.

\subsection{Data Collection Procedures, Instrument, and Quality Management}

A face to face interview using structured questionnaires was employed to collect primary data among all unit/department heads of the health facilities. The questionnaire was adopted from the performance of routine information system management framework assessment tool version 3.1. This PRISM tool is useful to get detailed information on the strengths and weaknesses of HIS in its input, process and output and identifies factors affecting its performance. It was prepared in English, translated to Amharic and then back to English by another person to ensure consistency. Two health professionals who are members of HIS monitoring team were assigned as supervisors. Six health professionals who had basic HMIS training and had prior experience on data collection were assigned as data collectors. To maintain data quality, during data collection period, the two supervisors and the principal investigators performed the supervision of data collection procedures on daily bases. Checked every completed questionnaire and gave onsite technical assistance to the data collectors. The data was checked for any missing values and completeness.

\subsection{Data Analysis}

The Collected data was checked for completeness, coded, entered and cleaned using STATA version 11. Analysis of data was done using the same package. Since all the variables were categorical frequency and percentages was computed to present the descriptive analysis. Associations between the dependent and independent variables were computed using binary logistic regression. A p-value $<0.05$ was considered as cut-off point for statistical significance.

To check whether the fitted model predicted well or not, the ROC Curve was analyzed and also Hosmer-Lemeshow test used to test overall goodness of fit. Multicollinearity in the variables was checked using Variance Inflation Factor (VIF).Interaction was also checked during the analysis.

\subsection{Ethical Issues}

Institutional ethical clearance was first sought from Mekelle University, college of health science. Data was collected after written consent from Dire Dawa regional health bureau. During the interview each participant were informed about the aim of the study. The interviewer discussed the issue of confidentiality and. Participants were informed that they have full right to refuse or discontinue participating in the research.

\section{Results}

\subsection{Descriptive Analysis}

Out of the total 239 respondents $188(78.7 \%$ ) were from 16 health centers, 28(11.7\%) were from health posts and the remaining 23(9.6\%) were from one referral hospital. Of the total departments included on this study 25(10.4\%) were from adult OPD, 12(5\%) were each from Emergency, Delivery and ART departments, 15(6.3\%) were from TB and Leprosy departments, 10(4.2\%) were from VCT departments and $15(6.3 \%)$ were from under 5 OPD (Table-1). 
Table 1. Distribution of units/departments heads of hospital, health centers and health posts in Dire Dawa Administration health facility, April 2013.

\begin{tabular}{lll}
\hline Unit/departments & Frequency & Percent \\
\hline VCT & 10 & 4.2 \\
Adult OPD & 25 & 10.4 \\
Under 5 OPD & 16 & 6.7 \\
Laboratory & 16 & 6.7 \\
Pharmacy & 16 & 6.7 \\
Family planning & 15 & 6.3 \\
ANC/PMCT & 15 & 6.3 \\
Emergency & 12 & 5.0 \\
Delivery & 12 & 5.0 \\
Environmental & 15 & 6.3 \\
EPI & 15 & 6.3 \\
TBL & 15 & 6.3 \\
ART & 12 & 5.0 \\
Ward/IPD & 9 & 3.8 \\
Statistics Unit & 8 & 3.3 \\
Health Facility & & \\
Unit/departments of health centers & 188 & 78.7 \\
Unit/departments of hospital & 23 & 9.6 \\
Units of health post & 28 & 11.7 \\
\hline
\end{tabular}

\subsection{HIS Input}

Majority $150(62.7 \%)$ and $154(64.4 \%)$ of the respondents reported that there was no assigned HIS personnel and separate HIS office in their department respectively. Majority, $195(81.6 \%)$ department heads reported there was no specific budget assigned for HIS. Around 125(52.3\%) of the respondents also revealed there was no legislative, regulatory and planning framework in their facility (Table-2).

Table 2. Health facility department's HIS inputs in Dire Dawa administration, April 2013.

\begin{tabular}{lll}
\hline & Yes & No \\
\cline { 2 - 3 } HIS input & Frequency (\%) & Frequency (\%) \\
\hline Personnel assigned to HIS & $89(37.2)$ & $150(62.7)$ \\
Separate unit assigned to HIS & $85(35.5)$ & $154(64.5)$ \\
Availability of equipment for HIS & $149(62.3)$ & $90(37.7)$ \\
Adequacy of equipments & $68(45.6)$ & $81(54.4)$ \\
Specific budget assigned for HIS & $44(18.4)$ & $195(81.6)$ \\
Mechanism to facilitate HIS & $117(49.0)$ & $122(51.0)$ \\
resource & $126(52.7)$ & $113(47.3)$ \\
HIS training for staffs & $114(48.0)$ & $125(52.0)$ \\
Planning framework to use HIS & & \\
Duration of training & $28(22.2)$ & \\
Less than 6 months & $30(23.8)$ & \\
6 months - 1 year & $68(54.0)$ & \\
More than 1 year &
\end{tabular}

\subsection{HIS Process}

One hundred ninety one (79.9\%) unit/department heads reported they collect health data on daily basis. Majority $196(82.0 \%)$ of departments also keep patient registration and HIS monthly reports. Among them 137(57.3\%) revealed the records were easily accessible to their staffs. Majority $164(68.6 \%)$ of heads also reported that they received directives in the last 3 months to check data accuracy, to fill format completely and submit the monthly report timely. In this study $185(77.4 \%)$ department heads claimed they submitted HIS report timely (Table 3 ).
Table 3. Health facility department's HIS process in Dire Dawa Administration, Apr. 2013.

\begin{tabular}{lll}
\hline \multirow{2}{*}{ HIS process } & Yes & No \\
\cline { 2 - 3 } & Frequency (\%) & Frequency(\%) \\
\hline Collecting data on daily activities & $191(79.9 \%)$ & $48(20.1 \%)$ \\
$\begin{array}{l}\text { Keep registration and copies of } \\
\text { HIS monthly report }\end{array}$ & $196(82.0 \%)$ & $43(18 \%)$ \\
$\begin{array}{l}\text { Accessibility of records for staffs } \\
\text { Procedures for distributing and }\end{array}$ & $148(62.0 \%)$ & $91(38.0 \%)$ \\
reporting data & $178(74.5 \%)$ & $61(25.5 \%)$ \\
$\begin{array}{l}\text { Data put at administrative level } \\
\text { Criteria for verification of }\end{array}$ & $205(85.7 \%)$ & $34(14.3 \%)$ \\
$\begin{array}{l}\text { completeness and consistency } \\
\text { Receive directives in the last } 3\end{array}$ & $181(75.7 \%)$ & $58(24.3 \%)$ \\
month & $164(68.6 \%)$ & $75(31.4 \%)$ \\
Timeliness of reported data & $185(77.4 \%)$ & $54(32.6 \%)$ \\
Completeness of reported data & $196(82.0 \%)$ & $43(18.0 \%)$ \\
Consistency of reported data & $188(78.7 \%)$ & $51(21.3 \%)$ \\
Representativeness of data. & $195(81.9 \%)$ & $44(18.1 \%)$ \\
\hline
\end{tabular}

\subsection{HIS Output}

Compiling of HIS data and reports containing HIS information was reported in $170(71.1 \%)$ and $162(67.8 \%)$ department heads respectively. Display of key indicators was reported in $145(60.7 \%)$ and quarterly and any other feedback reports were also available in 138(57.7\%) of departments. Regarding the use of health information for decision making, $156(65.3 \%)$ reported they use information to make decision. Among them $72(46.2 \%)$ use the information for future reference, $66(42.3 \%)$ use to observe trends of service delivery and $18(11.5 \%)$ to pass reports for other subsidy health offices respectively (Table -4 ).

Table 4. Health facility department's HIS output in Dire Dawa Administration, Apr. 2013.

\begin{tabular}{lll}
\hline \multirow{2}{*}{ HIS Output } & Yes & No \\
\cline { 2 - 3 } & Frequency (\%) & Frequency (\%) \\
\hline Department compile HIS data & $170(71.1 \%)$ & $69(28.9 \%)$ \\
$\begin{array}{l}\text { Compile any report containing } \\
\text { HIS information }\end{array}$ & $162(67.8 \%)$ & $77(32.2 \%)$ \\
$\begin{array}{l}\text { Display key indicators with tables } \\
\text { Presence of catchment area map }\end{array}$ & $145(60.7 \%)$ & $94(39.3 \%)$ \\
$\begin{array}{l}\text { Display summery of demographic } \\
\text { information }\end{array}$ & $163(68.2 \%)$ & $76(31.8 \%)$ \\
Availability of feedback or other & $138(57.7 \%)$ & $101(42.3 \%)$ \\
report on HIS data & $156(65.3 \%)$ & $83(34.7 \%)$ \\
Use HIS data for decision making & $62(26.0 \%)$ \\
Use HIS data for future reference & $72(46.2 \%)$ & \\
$\begin{array}{l}\text { Use HIS data to observe trends } \\
\text { Use HIS data to pass for subsidy }\end{array}$ & $66(42.3 \%)$ & \\
health office & $18(11.5 \%)$ & \\
$\begin{array}{l}\text { Present target \& performance } \\
\text { Calculation of area coverage }\end{array}$ & $147(61.5 \%)$ & $92(38.5 \%)$ \\
$\begin{array}{l}\text { Presence of routine review } \\
\text { meeting }\end{array}$ & $92(38.5 \%)$ & $147(61.5 \%)$ \\
$\begin{array}{l}\text { Incentive for information use } \\
\text { Policy for information use }\end{array}$ & $146(61.1 \%)$ & $93(38.9 \%)$ \\
$\begin{array}{l}\text { Dissemination mechanism of } \\
\text { health information }\end{array}$ & $67(28.1 \%)$ & $172(71.9 \%)$ \\
\hline
\end{tabular}

Based on the set criteria for HIS utilization, overall utilization rate was found to be $53.1 \%$. Utilization of HIS was also compared based on health facility type and from the 
analysis the highest utilization rate was $55.3 \%$ by the health centers and $52.2 \%$ in hospitals followed by $39.3 \%$ in health posts (Figure-1).

Technical determinant characteristics for HIS utilization.

Table 11 revealed that health departments which had standard set of indicators were 2.39 times $(\mathrm{COR}=2.390,95 \%$ CI [1.294, 4.415]) more likely utilized HIS than those departments which did not have standard indicators. Departments which had well designed format were 2.85 times more likely utilized HIS than those departments which did not have well designed format $(\mathrm{COR}=2.857$, 95\% CI [1.448, 5.637]). Similarly departments with friendly format for reporting were 3.12 times more likely utilize HIS than departments without friendly format $(\mathrm{COR}=3.122,95 \% \mathrm{CI}$ [1.671,5.831]). Health departments which had trained staffs to fill format were 3.98 times more likely utilize HIS than departments without trained staffs $(\mathrm{COR}=3.986,95 \% \mathrm{CI}$ [1.981,8.020]). Similarly health departments which had skilled human resource were 2.61 times more likely utilize HIS than departments without skilled human resource $(\mathrm{COR}=2.611,95 \% \mathrm{CI}[1.442,4.725])$. Departments which use appropriate technology for data analysis were $92 \%$ more likely utilize HIS than those departments which did not use technology for data analysis $(\mathrm{COR}=1.928,95 \% \mathrm{CI}$ [1.131,3.286]). However when they are adjusted with other predictor variables, only friendly format for reporting showed statistically significant association $(\mathrm{AOR}=2.796,95 \% \mathrm{CI}$ [1.478, 5.288]). Hence, departments with friendly format for reporting

Was 2.796 times more likely utilizing HIS than departments without friendly format.

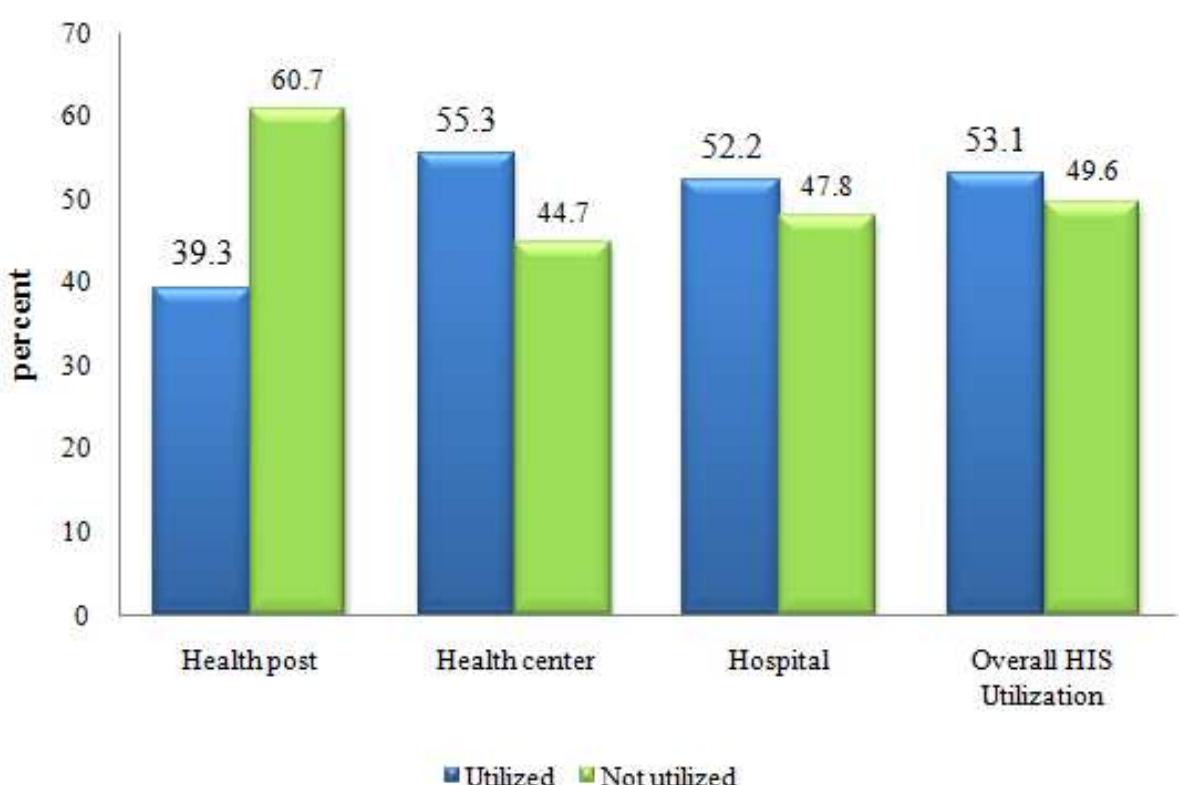

Figure 1. Utilization of HIS by health facility type in Dire Dawa Administration, Apr 2013.

Table 5. Associated Technical determinant characteristics for HIS utilization in all governmental health facilities at Dire Dawa Administration, Apr.2013.

\begin{tabular}{|c|c|c|c|c|c|}
\hline Technical characteristics & HIS utilization & COR & $95 \% \mathrm{CI}$ & AOR & $95 \% \mathrm{CI}$ \\
\hline Standard set of indicator. & $\begin{array}{l}\text { Agree } \\
\text { Disagree }\end{array}$ & $\begin{array}{l}2.390 \\
1^{R}\end{array}$ & $(1.294,4.415)$ & $\begin{array}{l}1.101 \\
1^{\mathrm{R}}\end{array}$ & $(0.514,2.391)$ \\
\hline Well designed format. & $\begin{array}{l}\text { Agree } \\
\text { Disagree }\end{array}$ & $2.8571^{\mathrm{R}}$ & $(1.448,5.637)$ & $\begin{array}{l}1.388 \\
1^{\mathrm{R}}\end{array}$ & $(0.616,3.153)$ \\
\hline Trained staff to fill format. & $\begin{array}{l}\text { Agree } \\
\text { Disagree }\end{array}$ & $3.9861^{\mathrm{R}}$ & $(1.981,8.020)$ & $\begin{array}{l}2.061 \\
1^{\mathrm{R}}\end{array}$ & $(0.911,4.661)$ \\
\hline Skilled human resource. & $\begin{array}{l}\text { Agree } \\
\text { Disagree }\end{array}$ & $2.6111^{\mathrm{R}}$ & $(1.442,4.725)$ & $\begin{array}{l}1.404 \\
1^{\mathrm{R}}\end{array}$ & $(0.672,2.905)$ \\
\hline Friendly format for reporting. & $\begin{array}{l}\text { Agree } \\
\text { Disagree }\end{array}$ & $3.1221^{\mathrm{R}}$ & $(1.671,5.831)$ & $\begin{array}{l}2.796 \\
1^{\mathrm{R}}\end{array}$ & $(1.478,5.288)^{*}$ \\
\hline Technology for data analysis. & $\begin{array}{l}\text { Agree } \\
\text { Disagree }\end{array}$ & $1.9281^{\mathrm{R}}$ & $(1.131,3.286)$ & $\begin{array}{l}1.293 \\
1^{\mathrm{R}}\end{array}$ & $(0.721,2.317)$ \\
\hline
\end{tabular}

$\mathrm{CI}=$ confidence interval $*=\mathrm{p}<0.05, \mathrm{COR}=$ Crude Odds Ratio, AOR $=$ Adjusted Odds Ratio

\subsection{Associated Organizational and Behavioral Characteristics for HIS Utilization}

Health departments in which their decision was based on supervisor directives were $82 \%$ more likely utilize HIS than departments in which their decision was not based on supervisor directives (COR=1.827, 95\%CI [1.023, 3.261]). Managers who provide regular feedback to their staff were 2.42 times more likely utilize HIS than managers who did not provide feedback, $\quad(\mathrm{COR}=2.420, \quad 95 \% \mathrm{CI}[1.362,4.302])$. 
Similarly managers who report on data accuracy regularly were $94 \%$ more likely utilize HIS than those managers who did not report data accuracy, $\quad(\mathrm{COR}=1.940,95 \% \mathrm{CI}$ [1.107,3.397]), however when they are adjusted with other variables only managers who provide regular feedback to their staffs was significantly associated with HIS utilization and these managers were 2.195 times more likely utilize HIS than managers who did not provide feedback( AOR=2.195, $95 \%$ CI[ $(1.213,3.974])$.

Table 6. Associated organizational and behavioral characteristics for HIS Utilization in all governmental health facilities at Dire Dawa Administration, Apr.2013.

\begin{tabular}{llccll}
\hline Possible Determinants & HIS Utilization & C OR & 95\% CI & A OR & 95\% CI \\
\hline Decision based on supervisor directive. & Agree & 1.827 & $(1.023,3.261)$ & 1.256 & $(0.664,2.362)$ \\
& Disagree & $1^{\mathrm{R}}$ & & $1^{\mathrm{R}}$ & \\
Managers provide regular feedback. & Agree & 2.420 & $(1.362,4.302)$ & 2.195 & $(1.213,3.974)^{*}$ \\
& Disagree & $1^{\mathrm{R}}$ & & \\
Manager report on data accuracy. & Agree & 1.940 & $(1.107,3.397)$ & 0.886 & $(0.773,2.312)$ \\
& Disagree & $1^{\mathrm{R}}$ & & $1^{\mathrm{R}}$ & \\
\hline
\end{tabular}

$\mathrm{CI}=$ confidence interval $*=\mathrm{p}<0.05, \mathrm{COR}=$ Crude Odds Ratio, AOR $=$ Adjusted Odds Ratio

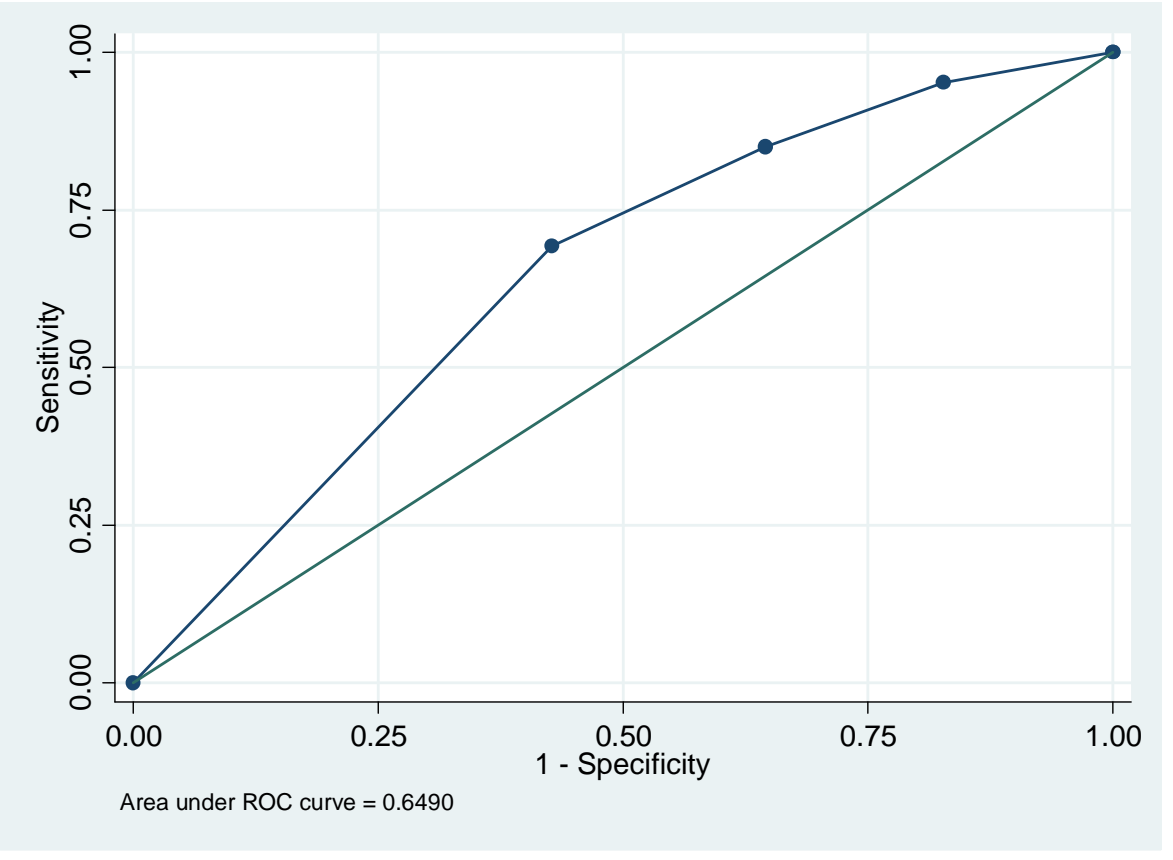

Figure 2. Model Adequacy goodness of fit

The area under the ROC curve (Figure-2) was 0.649 which suggests that the logistic regression model fairly predict (cutoff point=0.50). The significance value of HosmerLemeshow (Goodness-of-Fit) statistic was statistically insignificant $(p=0.992)$ which indicated that the model adequately fit the data. multicolinearity in the variables was checked using Variance Inflation Factor (VIF) and the calculated VIF was 1.03 which is less than 10 and this indicates there was no a problem of multicolinearity.

\section{Discussion}

Based on PRISM framework using HIS performance diagnostic tools, this study tried to assess the current status of HIS performance at health facility's HIS input, process and output and also tried to identify possible determinant of technical, organizational and behavioral factors for HIS utilization and data quality.

From the findings of this study $75 \%$ of units/departments reported that they had trained staffs and skilled human resources who were capable of performing HIS tasks. Though only $37 \%$ of departments reported there were specifically assigned personnel for HIS activity. Similarly $35 \%$ and $19 \%$ of the facilities have separated HIS office and assigned budget for HIS. These finding was somewhat comparable with other similar study in Bahr-Dar where 45\%, $43 \%$ and $21 \%$ was reported for availability of HIS personnel, HIS office and budget respectively in 2011[27], while only 23.8\% was reported for trained staff in North Gonder in 2006 [29] .Regarding availability of HIS equipment, 63\% had the necessary equipment. Whereas availability of coordination mechanism to facilitate the use of HIS resources and presence of regulatory and planning framework to use HIS were found to be below $50 \%$. This may be due to less 
concern given to these issues by majority of the facilities. Considering training on HIS activity, 53\% responded for availability of training. It is known that continuous training on HIS activity is important to create awareness, to have trained staff and skilled human resource that are confident and motivated to perform HIS task. When compared to a similar study conducted in Jimma, HIS training was below $50 \%$ in 2009 [26].

In order to check the accuracy of the data collected and report at the origin of data source, patient registration and copy of HIS monthly reports should be kept well. According to this study $90 \%$ of departments collect health data on daily activity and $82 \%$ keep patient registration and HIS monthly reports. These records were also easily accessible to staffs and easily retrieved in $67 \%$ of the departments. A similar study done in Jimma reported that all health departments collect data on daily activity and $73 \%$ keep their registration and monthly reports. Whereas the study conducted in Bahr Dar revealed that only $77 \%$ collect data on daily activity. In this study more than $74 \%$ of departments had clear procedure for distributing and reporting the collected data, $85 \%$ put the data at administrative level and $75 \%$ used a set of criteria to verify completeness and consistency of data before reporting. Regarding availability of supervision $69 \%$ of units/ departments had received supervisor directives to check data accuracy, to fill format completely and submit monthly report timely. This was higher when compared with similar studies where availability of supervision was reported below $50 \%$ in Bahr-Dar and North Gonder respectively. This may be due to the fact that majority of the health facilities were easily reachable for supervision.

Accurate, consistent, complete and timely information is essential for public health decision-making and action-taking such as policy making, planning, programming and monitoring [13]. In this study $77.4 \%$ department heads agreed reports were submitted according to the schedule, which is within $20^{\text {th }}$ to $22^{\text {nd }}$ days of the month for health post and $20^{\text {th }}$ to $24^{\text {th }}$ for health centers and hospital. There was $82.0 \%$ department heads also claimed reports were completely filled before reporting while $78.7 \%$ of these reports was agreed to be consistent. A similar study in North Gonder showed only 50\% HMIS reports were submitted timely while $96 \%$ of these reports were completely filled in 2006. Consistency of reports in this study area was slightly high compared to the study in Jimma where $62 \%$ of respondents claimed consistency of reports in 2009. This increment may be due to the fact that majority of units/departments had basic HIS training, which in turn had skilled human resource to perform HIS tasks in improving data quality and information use. Another reason could be due to availability of good supervision and feedback given by senior supervisors in this study area.

As originally proposed, HIS performance is defined as improved data quality and continuous use of information. In addition Use of information depends upon the decision power of the people and the importance given to other considerations despite the availability of information [15].
From the finding of this study $71.1 \%$ and $67.8 \%$ of units/departments compile HIS data and report containing HIS information respectively. It is known that health departments are the primary producers of data and are expected to change this data in to information at the site of data generation. This information is used for evidence based decision making for planning, budget allocation, monitoring and evaluation of program to take immediate action. So based on the set criteria for HIS utilization the overall utilization was found to be $53.1 \%$. This finding was higher when compared with other similar studies in which only 22.5\% HIS utilization was reported in North Gonder, $32.9 \%$ in Jimma, 45.6\% in Bahr Dar, and 44.6\% reported in Malawi. On the other hand this finding could be strengthened by the report of progress and lessons on HMIS/M\&E implementation from pioneer regions (including Dire Dawa) in 2008 showed that health facilities implementing the new HMIS and M\&E achieved considerably high improvements in data quality, information management, and reporting and information use [33].

About $61 \%$ units reported there was routine meeting for reviewing managerial and administrative matters. This was higher compared to the assessment report on data quality and information use in selected health facilities in 2011 where only $23.5 \%$ facilities had routine review meeting [30]. In this study availability of incentives and policy for information use were found to be below $40 \%$. A similar finding was reported on the study conducted in Bahr Dar where only $18.3 \%$ and $42.9 \%$ reported for availability of incentives and policy respectively.

Although the PRISM framework allows identifying determinant factors for HIS utilization and data quality, due to lack of similar studies conducted using this framework, it did not allow comparison of the identified determinant factors between different studies.

Among the technical variables friendly format for reporting was found to be significant predictor for HIS utilization. This might be explained by friendly format increase the motivation and confidence of health professionals in performing HIS tasks and saves their time during reporting. Whereas among behavioral and organizational factors managers provide regular feedback to their staffs was also found to be determinant factors for HIS utilization. This might be due to the fact that if there is feedback mechanism, departments will identify their strength and weakness.

\section{Acknowledgements}

We are grateful to all research team who dedicated their full time and effort during data collection. We would like to thank Dire Dawa Administrative Health Bureau for their cooperation in undertaking this research and also all department heads of hospital, health centers and health posts for their participation and support in providing the required information for this research. 


\section{References}

[1] World Health Organization Regional Office for the Western Pacific. Workshops on the assessment and development of national Health Information Systems (HIS) and epidemiological surveillance, WHO 1986.

[2] Chawla R, Bansal AK, Indrayan A. Informatics Technology in Health Care, Nati Med 1997, vol.10 (1): pp31-5.

[3] http//www.who.int/entity/healthmetrics/hmn. Accessed at12:39 12/08/2012

[4] Rwanda Health Information System Assessment Report, RTI international 2006, USAID/Ministry of Health, Rwanda.

[5] Developing Health Management Information System. A practical guide for developing countries, WHO 2004.

[6] WHO, A Framework and Standards for Country Health Information System Development. Geneva; WHO, 2008.

[7] HMIS Reform Team. Health Management Information System / M\&E: Information Use Guidelines and Display Tools, Federal Ministry of Health 2007.

[8] GAVI/core: Monitoring national immunization system using core indicators

[9] Tullen University. Tullen University supported HMIS Implementation program Training Manual 2009; Addis Ababa.

[10] Sahay Sundeep. Special Issues on IT and Health Care in Developing Countries, Department of Informatics, University of Oslo 2001, Norway.

[11] Health Metrics Network. Assessing the National Health Information System: An Assessment Tool version 4.

[12] World Health Organization. Assessment of Ethiopian National Health Information System; Final report, 2007.

[13] Lippeveld T, Sauerborn R, Bodart C. Design and implementation of health information systems: World Health Organization 2000, Geneva.

[14] Health Facility's Revised Health Management Information System (HMIS) procedural manual volume-one, Uganda 2010.

[15] Aqil A, Lippeveled T, Dairiku H. PRISM framework: a paradigm shift for designing, strengthening and evaluating routine health information systems; Health Policy and Planning 2009.

[16] MEASURE Evaluation-PRISM: Performance of Routine Information System Management Framework

[17] World Health Organization. Monitoring the building blocks of health systems: a handbook of indicators and their measurement strategies, WHO 2010, Geneva, Switzerland.

[18] Ajzen I. Laws of human behavior: symmetry, compatibility, and attitude-behavior correspondence, 2005 ..

[19] Odhiambo-Otieno GW. Evaluation criteria for district health management information systems: lessons from the Ministry of Health, Kenya. International Journal of Medical Informatics 2005b. vol.74: pp31-8.

[20] Hackman JR, Oldham GR. Work redesign. Reading, MA: Addison-Wesley, 1980.

[21] Mavimbe JC, Braa J, Bjune G. Assessing immunization data quality from routine reports in Mozambique. BMC Public Health2005. Vol. 11: pp108.

[22] Da Silva AS, Laprega MR. Critical evaluation of the primary care information system (SIAB) and its implementation in Ribeiero Preto, Sau Paulo, Brazil. Cadernos de Saude Publica 2005. Vol.21: pp1821-8.

[23] Mapatano MA, Piripiri L. Some common errors in health information system report (DR Congo). Sante' Publique 2005. Vol.17: pp551-8.

[24] Odhiambo-Otieno GW. Evaluation of existing district health management information systems: a case study of the district health systems in Kenya. International Journal of Medical Informatics 2005. vol.74: pp733-44.

[25] Nsubuga P, Eseko N, Tadesse W et al. Structure and performance of infectious disease surveillance and response, United Republic of Tanzania, 1998. Bulletin of the World Health Organization2002. Vol. 80: pp196-203

[26] Aqil A, Hotchkiss D, Lippeveld T, Mukooyo E, Asiimwe S. Do the PRISM framework tools produce consistent and valid results? A Uganda study. Working Paper. National Information Resource Center, Ministry of Health, Uganda; MEASURE Evaluation, 2008.

[27] Peter K, Miriam N, Amos N. Development of HMIS in poor countries: Uganda as case study; UMU press 2005, vol.3 (1).pp48-50.

[28] Sultan A, Challi J, Waju B. Utilization of Health information System at district level in Jimma zone, Ethiopian Journal of health science 2011, vol.21: PP.75-79.

[29] Helen T. assessment of the Health Management information System implementation Status in public health facilities in Bahir-Dar city. Master's thesis, school of information science, Addis Ababa University, 2011.

[30] Gebrekidan M, Negus W, Hajira M. Data Quality and Information use: a systematic review to improve evidence in Ethiopia, African health Monitor 2011, Issue No.14 (http/www.aho.afro.who.int/en/ahm/issue14)

[31] Gashaw A. Assessment of utilization of Health Information System at district level with particular emphasis to HIV/AIDS program in North Gonder, Master's thesis, department of community health medical faculty, Addis Ababa University 2006.

[32] HMIS task force. SNNP Regional Government, 2011. http//www.snnprhb.gov.et

[33] Woldemariam H, Habtamu T, Fekadu N, Habtamu A. Implementation of an integrated Health Management Information System and Monitoring and Evaluation (HMIS/M\&E) system in Ethiopia: progress and lessons from pioneering regions; Quarterly health Bulletin 2010, vol,3(1): pp48-52.

[34] Central Statistics Agency of Ethiopia, 2007. 